\title{
PENGARUH KOMPETENSI SUPERVISOR DAN PENGHARGAAN TERHADAP MOTIVASI KERJA PERAWAT DI RUANG RAWAT INAP RUMAH SAKIT PERMATA BUNDA TAHUN 2018
}

\section{The Influence Of Supervisor Competency And Awards On Nursing Work Motivation In The Permata Bunda Hospital In 2018}

\author{
Muhammad Sofyan ${ }^{1}$, Destanul Aulia ${ }^{2}$, Fazidah Aguslina Siregar ${ }^{3}$ \\ ${ }^{1}$ Fakultas Ilmu Kesehatan Masyarakat, Universitas Sumatera Utara \\ ${ }^{2}$ Fakultas Ilmu Kesehatan Masyarakat, Universitas Sumatera Utara \\ ${ }^{3}$ Fakultas Ilmu Kesehatan Masyarakat, Universitas Sumatera Utara
}

\begin{abstract}
Abstrak
Dalam asuhan keperawatan, perawat harus memiliki kemampuan dan motivasi untuk memberikan layanan terbaik. Dengan kemampuan dan motivasi, perawat akan terdorong untuk melakukan pekerjaannya dengan baik. Survei awal yang dilakukan di Rumah Sakit Permata Bunda, menemukan bahwa lebih dari $45 \%$ perawat tidak senang dengan gaya kepemimpinan kepala ruangan yang didominasi oleh metode otoriter. Selain itu, ditemukan bahwa 27 (90\%) dari 30 perawatan masih memiliki lowongan. Sampel dan populasi penelitian ini adalah seluruh perawat yang bekerja di bangsal rawat inap Rumah Sakit Permata Bunda Kota Medan yaitu sebanyak 106 orang. Metode analisis data dalam penelitian ini menggunakan analisis regresi logistik. Hasil analisis multivariat menunjukkan bahwa variabel kompetensi supervisor memiliki nilai $p=0,056$ dan OR 3,201 , yang berarti bahwa kompetensi superviso memiliki pengaruh terhadap motivasi kerja perawat dan kompetensi pengawas yang baik akan meningkatkan motivasi kerja perawat sebesar 3,2 kali. Saran kepada pimpinan rumah sakit untuk meningkatkan kualitas pengawasan untuk meningkatkan motivasi kerja perawat yang akan mempengaruhi peningkatan kualitas kerja dan kualitas pelayanan.
\end{abstract}

Kata Kunci: Motivasi Kerja, Kompetensi Supervisor, dan Penghargaan

\begin{abstract}
In nursing care, nurses must have the ability and motivation to provide the best service. With ability and motivation, nurses will be encouraged to do their jobs well. The initial survey conducted at Permata Bunda Hospital, found that more than $45 \%$ of nurses were unhappy with the leadership style requested by the authoritarian. In addition, it was found that $27(90 \%)$ of 30 treatments still had vacancies. The sample and population of this study were all nurses working in the inpatient ward of Permata Bunda Hospital, Medan City, namely 106 people. Data analysis in this study used logistic regression analysis. The results of multivariate analysis show that the supervisor competency variable has a value of $\mathrm{p}=0.056$ and OR 3.201, which means that superviso has an influence on work and a good salary will increase nurses' work motivation by 3.2 times. Suggestions for making hospitals to improve the quality of supervision to improve work that will affect the improvement of work quality and service quality.
\end{abstract}

Keywords: Work Motivation, Supervisor Competence, and Award

$\begin{array}{ll}\text { Korespondensi } & \text { : Muhammad Sofyan } \\ \text { Email } & \text { : muhammadsofyan60@gmail.com }\end{array}$




\section{PENDAHULUAN}

Perawat merupakan salah satu tenaga kesehatan yang terpenting dalam ruang lingkup manajemen rumah sakit (1). Selain itu juga perawat merupakan tenaga kesehatan yang berinteraksi langsung terhadap pasien selama 24 jam. Tidak hanya itu peran-peran lain juga di harus dimiliki oleh perawat diantaranya sebagai mitra kerja, narasumber (resources person), pendidik (teacher), kepemimpinan (leadership)

Kepemimpinan merupakan bentuk dominasi yang didasari atas kemampuan pribadi yang sanggup mendorong atau mengajak orang lain untuk berbuat sesuatu yang berdasarkan penerimaan oleh kelompoknya, dan memiliki keahlian khusus yang tepat bagi situasi yang khusus pula (3).

Gaya kepemimpinan akan di terapkan dalam suatu manajemen untuk dapat menciptakan suatu efektifitas kerja yang positif bagi pelayanan (4). Gaya kepemimpinan seorang kepala ruangan ada 4 jenis, dimana setiap ruangan berbeda kondisi akan berbeda pula gaya kepemimpinannya. Di antaranya ialah otoriter, demokratis, partisipatif, bebas tindak (5). Didalam keperawatan, kepemimpinan merupakan penggunaan keterampilan seorang pemimpin (perawat) dalam mempengaruhi perawatperawat lain yang berada di bawah pengawasannya. Salah satu fungsi manajerial dari seorang kepala ruang adalah dengan melakukan pengawasan supervisi yang baik (6).

Supervisi adalah merencanakan, mengarahkan, membimbing, mengajar, mengobservasi, mendorong, memperbaiki, mempercayai, mengevaluasi secara terus menerus pada setiap perawat dengan adil dan bijaksana (7). Tujuan utama supervisi adalah untuk lebih meningkatkan kinerja bawahan bukan untuk mencari kesalahan (8). Peningkatan kerja ini dilakukan dengan teknik langsung dan tidak langsung (9).

Beberapa hal yang mempengaruhi kinerja ialah faktor kemampuan (ability) dan faktor motivasi (motivation). Dalam memberikan asuhan keperawatan kepada pasien, perawat harus memiliki kemampuan dan motivasi untuk meningkatkan dan mendorong perawat memberikan pelayanan yang terbaik kepada pasien. Dengan adanya kemampuan dan motivasi, perawat akan terdorong untuk melakukan tugas-tugasnya dengan baik. Motivasi bersumber dari dorongan dalam diri maupun dari luar diri perawat (10). Teori herzberg menyatakan bahwa motivasi terbagi dua bagian,yaitu faktor Ekstrinsik dan Intriksik. Motivasi ekstrinsik meliputi : supervisi, kondisi kerja, gaji, hubungan dengan rekan sejawat, hubungan dengan bawahan, status dan keamanan. Faktor intriksik meliputi: prestasi, pengakuan kerja, bekerja sendiri, tanggung jawab, kemajuan dalam pekerjaan, dan pertumbuhan (11).

Berdasarkan hasil survey awal yang dilakukan peneliti di ruang rawat inap Rumah Sakit Umum Permata Bunda, Jumlah pasien rawat inap seluruh ruangan pada tahun 2016 sebanyak 6.485 dengan Bed Occupancy Ratio (BOR) 64-74\%, Turn Over Interval (TOI) 4hari, berdasarkan hasil wawancara terhadap 20 orang perawat bahwasanya ditemukan lebih dari $45 \%$ perawat tidak senang dengan gaya kepemimpinan kepala ruangan yang mendominasi dengan cara memerintah (otoriter). Selain itu juga dapat di lihat dari survey awal peneliti dengan 
mengobservasi 30 rekam medis asuhan keperawatan rawat inap tahun 2017. Ditemukan bahwa sebanyak 27 (90\%) asuhan keperawatan masih belum terisi dengan baik dan masih terdapat kekosongan pada form yang telah tersedia.

Selain itu juga perawat mengatakan bahwa mereka tidak pernah mendapatkan reward ataupun penghargaan dari kepala ruangan jika salah satu perawat melakukan tugasnya dengan baik dibandingkan dengan perawat yang lain. Mereka mengatakan bahwa tidak ada perbedaan antara satu perawat dengan perawat yang lain dan bahwa semuanya sama bagi kepala ruangan, kepala ruangan hanya memeriksa tugas mereka dan memberikan teguran jika ada perawat yang kurang baik dalam melakukan asuhan keperawatan. Tidak ada perlakuan khusus bagi perawat yang melaksanakan tugas lebih baik.

Berdasarkan latar belakang di atas maka peneliti tertarik untuk mengetahui bagaimana "Pengaruh kompetensi supervisor, penghargaan dan kondisi lingkungan kerja terhadap motivasi kerja perawat ruang inap di Rumah Sakit Permata Bunda Medan.

\section{METODE}

Jenis penelitian ini adalah penelitian analitik kuantitatif dengan desain penelitian cross sectional yang dilaksanakan di Rumah Sakit Umum Permata Bunda Kota Medan berlokasi di Jalan Sisingamangaraja no.7 Medan, dimulai dari Juni 2018 hingga Oktober 2018. Populasi dalam penelitian ini adalah perawat yang bekerja di instalasi rawat inap Rumah Sakit Umum Permata Bunda Kota Medan sebanyak 106 orang.
Berdasarkan perhitungan diatas sampel yang mejadi responden dalam penelitian ini disesuaikan menjadi sebanyak 81 orang atau sekitar $76 \%$ dari seluruh perawat Rumah Sakit Permata Bunda, kemudian peneliti menimbang dengan jumlah keseluruhan populasi maka jumlah sampel kemudian ditetapkan menjadi 106 orang atau $100 \%$ dari jumlah populasi. Hal ini dilakukan untuk mempermudah dalam pengolahan data dan untuk hasil pengujian yang lebih baik (12).

Analisis data dilakukan secara bertahap yaitu analisis univariat, bivarait dan multivarait. Analisis univariat ini dilakukan untuk menjelaskan karakteristik masingmasing variabel yang diteliti. Data yang dihasilkan dalam penelitian ini adalah data kategorik, sehingga analisis univariat dilakukan dengan menggunakan distribusi frekuensi dari masing-masing variabel yang diteliti (13).

Analisis bivariat dilakukan untuk mengetahui hubungan antara 2 variabel, yaitu variabel independen dan variabel dependen dalam penelitian ini. Hubungan yang dicari adalah hubungan-hubungan seperti yang tertuang dalam tujuan khusus penelitian. Data yang dihasilkan dalam penelitian ini adalah data kategorik, sehingga untuk hubungan antara kedua variabel tersebut dilakukan uji statistik Kai Kuadrat (Chi Square). Kemaknaan perhitungan statistik dilihat dengan menggunakan batas kemaknaan (p) sebesar 0,05. Bila p value $<=0,05$ maka Ho ditolak, yaitu ada hubungan antara kedua variabel yang diuji. Sebaliknya, bila $\mathrm{p}$ value> 0,05 maka Ho gagal ditolak, yaitu tidak ada hubungan antara kedua variabel yang diuji (14). 
Selanjutnya, analisis multivariat dilakukan untuk mengetahui variabel independen mana yang paling berpengaruh dalam berkorelasi dengan variabel dependen. Analsis multivariat yang digunakan dalam penelitian ini adalah analisis Regresi logistic.

\section{HASIL PENELITIAN}

Berdasarkan hasil analisis dapat diketahui bahwa dari 106 responden yang diamati, mayoritas berjenis kelamin perempuan yaitu ada sebanyak 94 responden $(88,7 \%)$, berumur $<30$ tahun yaitu ada sebanyak 50 responden $(47,2 \%)$, dengan tingkat pendidikan D3 keperawatan yaitu ada sebanyak 79 responden $(74,5 \%)$, sudah menikah yaitu sebanyak 72 responden $(67,9 \%)$, dan sudah bekerja lebih dari lima tahun yaitu ada sebanyak 25 responden $(61,0)$.

\section{Tabel 1.Distribusi Frekuensi Berdasarkan Data Karakteristik Responden}

\begin{tabular}{clcc}
\hline No & Variabel & n & \% \\
\hline 1 & Jenis Kelamin & 94 & 88,7 \\
& Perempuan & 12 & 11,3 \\
& Laki-laki & $\mathbf{1 0 6}$ & $\mathbf{1 0 0}$ \\
\hline & Total & 50 & 47,2 \\
\hline 2 & Kelompok Umur & 46 & 43,4 \\
& < 30 Tahun & 10 & 9,4 \\
& 30-50 Tahun & $\mathbf{1 0 6}$ & $\mathbf{1 0 0}$ \\
& $>$ 50 Tahun & & \\
\hline & Total & 79 & 74,5 \\
\hline 3 & Pendidikan & 6 & 5,7 \\
& D3 & 8 & 7,5 \\
& Keperawatan & 13 & 12,3 \\
& D4 Kebidanan & & $\mathbf{1 0 0}$ \\
& S1 Keperawatan & $\mathbf{1 0 6}$ & 67,9 \\
& SPK & & 32,1 \\
\hline & Total & 72 & $\mathbf{1 0 0}$ \\
\hline 5 & Status & 34 & 39,0 \\
& Perkawinan & & 61,0 \\
& Menikah & $\mathbf{1 0 6}$ & $\mathbf{1 0 0}$ \\
& Belum Menikah & &
\end{tabular}

Berdasarkan hasil analisis chi square diperoleh kedua variabel mempunyai nilai $\mathrm{p}<\alpha(0,05)$. Maka dapat disimpulkan bahwa variabel kompetensi supervisor dan penghargaan memiliki hubungan yang signifikan dengan variabel dependen motivasi kerja. 


\section{Tabel 2. Hubungan Kompetensi Supervisor dan Penghargaan dengan Motivasi Kerja Perawat}

\begin{tabular}{lc}
\hline Variabel & p value \\
\hline Kompetensi & 0,018 \\
Supervisor & 0,033 \\
Penghargaan & \\
\hline
\end{tabular}

Analisis multivariat adalah analisis yang bertujuan untuk mengetahui besar pengaruh dari beberapa variabel independen terhadap variabel dependen secara bersamaan. Variabel yang dapat masuk ke tahap multivariat adalah variabel yang pada saat analisis bivariatnya memiliki nilai $\mathrm{p}<0,25$. Berdasarkan hasil analisis, dipeoleh kedua variabel memiliki nilai $\mathrm{p}<0,25$ maka selanjutnya dapat dilanjutkan ke tahap multivariat.

\section{Tabel 3 Pengaruh Beban Kerja dan Komitmen dengan Performance Rekam Medis}

\begin{tabular}{lccc}
\hline \multicolumn{1}{c}{ Variabel } & $\begin{array}{c}\text { p } \\
\text { value }\end{array}$ & OR & Interval Kepercayaan (95\%) \\
\hline Kompetensi & 0,005 & 3,201 & $0,461-9,616$ \\
$\begin{array}{l}\text { Supervisor } \\
\text { Penghargaan }\end{array}$ & 0,206 & 1,143 & $0,627-4,527$ \\
\hline
\end{tabular}

\section{PEMBAHASAN}

Dari hasil analisis menunjukkan bahwa hanya variabel kompetensi supervisor yang memilki nilai $\mathrm{p}<\alpha(0,05)$, artinya variabel kompetensi supervisor memilki pengaruh yang signifikan terhadap variabel motivasi kerja perawat. Selanjutnya, pada nilai Odds Ratio (Exp B) dari variabel kompetensi supervisor adalah sebesar 3,2, hal ini bermakna bahwa kompetensi supervisor yang baik akan dapat meningkatkan motivasi kerja perawat sebesar 3,2 kali lebih tinggi dibandingkan dengan kompetensi supervisor yang tidak baik.

Hasil penelitian ini sejalan dengan yang dilakukan oleh Wuryanto (2007) di Rumah sakit umum Dr. Adiatma di Kota Semarang pada bulan November 2007 menyebutkan bahwa sebagian besar kepala ruang mengelola ruangan dengan gaya kepemimpinan otoriter (15). Hasil penelitian Hutahaen tahun 2009 di rumah sakit umum pusat haji adam malik medan, didapatkan gaya kepemimpinan yang sering dipakai kepala ruang adalah demokrasi sebesar (50\%) (16). Penelitian yang dilakukan oleh Natalia dan Tarigan (2010) di Rumah Sakit TK II Putri Hijau medan mayoritas perawat memiliki kinerja baik dalam pemberian asuhan keperawatan (71\%) dan kinerja buruk (29\%) (17).

Victor (2011), gaya kepemimpinan memiliki pengaruh positif terhadap kinerja perawat di Rumah Sakit kota Ambon (18). Sedangkan penelitian yang dilakukan oleh Swasty tahun 2011 di Rumah Sakit Islam Surabaya menunjukkan sebagian besar (72\%) kepala ruangan di Rumah Sakit Islam 
Surabaya menerapkan gaya kepemimpinan otoriter dan menghasilkan $(60,7 \%)$ perawat pelaksana memiliki kinerja yang cukup. Dari penelitian lain yang dilakukan oleh Pratama (2017) di rumah sakit Tk. IV Pematang Siantar dapat disimpulkan bahwa terdapat pengaruh signifikan tanggung jawab, kesempatan untuk maju, dan pengakuan terhadap kinerja perawat pelaksana (19).

Hasil penelitian-penelitain di atas sejalan dengan hasil penelitian yang dilakukan Margareth, dkk (2016) dengan masalah hubungan antara insentif, motivasi, supervisi dengan kinerja perawat di ruang rawat inap Rumah Sakit Umum Daerah Kabupaten Sorong Papua Barat dengan jumlah sample 68 perawat. Hasil menunjukkan bahwa insentif, motivasi, dan supervisi secara bersama-sama berhubungan dengan kinerja perawat di ruang rawat inap Rumah Sakit Umum Daerah Kabupaten Sorong Papua Barat (20).

\section{KESIMPULAN DAN SARAN}

Ada pengaruh variabel kompetensi supervisor terhadap motivasi kerja perawat di ruang rawat inap RS Permata Bunda Medan. Kompetensi supervisor yang baik akan dapat meningkatkan motivasi kerja perawat sebesar 3,2 kali lebih tinggi dibandingkan dengan kompetensi supervisor yang tidak baik.

Disarankan kepada pimpinan Rumah Sakit agar memperbaiki kualitas supervisi agar dapat meningkatkan motivasi kerja perawat sehingga yang nantinya akan berdampak pada peningkatan kinerja perawat dan kualitas pelayanan yang lebih baik lagi.

\section{DAFTAR PUSTAKA}

1. Undang-Undang Republik Indonesia No. 36 tahun 2009 tentang kesehatan.

2. Gibson JL, Wahid D. Struktur Organisasi dan Manajemen. Jakarta: Pusat Kajian Ekonomi Kesehatan FKM Universitas Indonesia; 2002

3. Mangkunegara. (2014). Manajemen sumber daya manusia perusahaan. Bandung: Remaja Rosdakarya.

4. Handoko, (2001). Manajemen Personalia dan Sumber Daya Manusia. Yogyakarta : BPFE Press.

5. Muninjaya, A.A.G. 2012. Manajemen mutu pelayanan kesehatan. Jakarta: EGC

6. Arwani, Supriyatno. (2006). Manajemen Keperawatan di Bangsal. Jakarta; EGC

7. Muhith, A. (2014). Pengembangan model mutu asuhan keperawatan (Edisi ke-2). Yogyakarta: Threepreuner.

8. Marnis, P. (2014). Manajemen sumber daya manusia. Surabaya: Zifatama Publisher.

9. Suarli dan bachtiar. 2010. Manajemen keperawatan dengan pendekatan praktis. Jakarta; Erlangga

10. Mangkunegara. (2014). Evaluasi kinerja SDM. Bandung: Reflika Aditama

11. Nursalam, 2011. Manajemen keperawatan (aplikasi dalam praktik keperawatan profresional edisi 3). Jakarta; Salemba medika

12. Sugiyono. (2015). Statistik untuk Penelitian. Bandung: Alfabeta

13. Gulo, W. (2013). Metodologi penelitian. Jakarta: Gramedia Widiasarana Indonesia.

14. Notoatmodjo,S. 2012. Metodologi Penelitian Kesehatan. Jakarta: Rineka Cipta. 
15. Wuryanto, Edy. Hubungan Antara Kualitas Kepemimpinan dan Gaya Manajemen Dengan Kepuasan Kerja Perawat di Rumah Sakit Umum dr. Adiatma Kota Semarang. 2007;3(2), 74-81

16. Hutahean. 2009. Pengaruh Gaya Kepemimpinan Kepala Ruangan Terhadap Semangat Kerja Perawat Pelaksana di Ruang Inap RSUP. Haji Adam Malik Medan (Tesis, Universitas Sumatera Utara).

17. Natalia, Tarigan. Kinerja Perawat Dalam Pemberian Asuhan Keperawatan Di Rumah Sakit Tk II Putri Hijau Medan. 2010; 1(2) 29-34

18. Pattisiana, Victor. 2011. Pengaruh Gaya Kepemimpinan Transformasional Terhadap Kinerja Pelayanan Dengan Budaya Kerja Dan Good Corporate Governance Sebagai Variabel Moderasi (Tesis, Universitas Brawijaya).

19. Pratama, Muchti Yuda. Pengaruh Motivasi Intrinsik Terhadap Kinerja Perawat Pelaksana Di Rumah Sakit Tk. IV Pematang Siantar. 2017; 2(1), 78-89.

20. Margareth, Renyaan. Hubungan Antara Insentif, Motivasi, Supervisi Dengan Kinerja Perawat Di Ruang Rawat Inap Rumah Sakit Umum Daerah Kabupaten Sorong-Papua Barat. 2016 2(1) 68-74 